\title{
Keratoconus: Challenges and Emerging Trends
}

Karamichos $\mathbf{D}^{1,2^{*}}$

${ }^{1}$ Department of Ophthalmology, Dean McGee Eye Institute, University of Oklahoma Health Science Center, Oklahoma City, USA

${ }^{2}$ Department of Cell Biology, University of Oklahoma Health Sciences Center, Oklahoma City, USA

*Corresponding author: Dr. Dimitrios Karamichos, Department of Ophthalmology, Dean of McGee Eye Institute, University of Oklahoma Health Sciences Center, Oklahoma City, OK 73104, USA, Tel: 405271 4019, Fax: 405271 8128; E-mail: dimitrios-karamichos@ouhsc.edu

Rec date: September 18, 2018; Acc date: September 29, 2018; Pub date: September 30, 2018

Copyright: ( 2018 Karamichos D. This is an open-access article distributed under the terms of the creative commons attribution license, which permits unrestricted use, distribution, and reproduction in any medium, provided the original author and source are credited.

\section{Introduction}

Keratoconus (KC) is a bilateral corneal dystrophy that affects $1: 400$ - 1:2000 people worldwide. It is thought to be multifactorial with the onset linked to genetic, environmental, biomechanical, and hormonal cues. Because of the multiple factors involved, KC pathophysiology remains a mystery. $\mathrm{KC}$ is known to manifest during puberty and develop at different, unexplained rates amongst individuals. KC affects both males and females, as well as different ethnicities with a higher prevalence towards Asian populations. There are several ocular associations reported in literature including; retinitis pigmentosa, microcornea, ectopia lentis, lenticonus, macular coloboma, and floppy eyelid syndrome. Systemic associations are also known including; Down's syndrome, Ehlers-Danlos syndrome, and mitral valve prolapsed.

Several approaches have been deployed, in vitro and in vivo in order to determine the reason(s) that the human keratoconic cornea thins and protrudes. Genetic studies are perhaps the largest, in terms of participants/patients. Multiple genes have been proposed, including, VSX, COL1A1, COL5A1, and LOX, but studies remain inconclusive [1-13]. As a result, we have yet to see the development of an animal model that recapitulates the KC phenotype. These hurdles have hampered our progress towards unravelling the key molecular mechanisms responsible for the KC onset and progression. Perhaps the biggest gap in our knowledge about $\mathrm{KC}$ is that very few studies have attempted to link in vitro findings to those in vivo.

\section{Sex hormones}

Sex hormones are known to play a role in the maintenance of the structure and integrity of the human cornea. Hormone levels have been reported to alter corneal thickness, curvature, and sensitivity during different times of the menstrual cycle and pregnancy. Furthermore, the presence of hormones in the human tear film has also been reported. Surprisingly, the role of sex hormones in corneal diseases has not been investigated. Our group recently suggested that $\mathrm{KC}$ is at least partially a systemic disease. We reported hormone alterations in the $\mathrm{KC}$-derived corneal stromal cells as well as in human KC saliva [14]. Since then, our work is spearheading the field with what we believe is the discovery of the first-ever $\mathrm{KC}$ biomarker. If we are correct about our hypothesis, and our gene candidate is truly a $\mathrm{KC}$ biomarker, it could transcend the landscape of $\mathrm{KC}$ research, $\mathrm{KC}$ treatment, and $\mathrm{KC}$ care.

\section{Prolactin-induced protein}

Prolactin-Induced Protein (PIP) is also known as gross cystic disease fluid protein 15 (GCDFP-15), extra-parotid glycoprotein (EP$\mathrm{GP}$ ), and gp17 seminal actin-binding protein (SABP) [15-17]. PIP is tightly linked to sex hormones and is the connection that initiated our hypothesis that PIP may be involved in KC pathogenesis. PIP is upregulated by androgens and downregulated by estrogens, although the exact downstream signaling pathway(s) is not yet well defined.

PIP was originally discovered as a marker for both benign and malignant apocrine metaplasia, considering that the protein is not normally expressed in healthy breast tissue [18]. In KC, we were the first to report PIP modulation, showing significant downregulation in both KC-derived corneal stromal cells and KC tear fluids, when compared to healthy controls [19]. This was intriguing, especially in regard to the interplay between PIP and sex hormones, and the effects of hormonal imbalances in the human cornea (ex. corneal thinning during pregnancy). Amazingly, the role of sex hormones in KC had never been investigated in depth, prior to our studies. Our recent comprehensive review on PIP and $\mathrm{KC}$ highlights this emerging topic [20].

\section{Future Implications}

Our recent findings spearhead the work done in the $\mathrm{KC}$ field with regard to biomarker discovery and validation. Defining a universally agreed upon path for biomarker validation is urgently needed to circumvent many of the hurdles faced in KC prognosis.

If PIP is confirmed as a biomarker, a clinical test/exam could be quickly implemented for any individual that is suspected to have KC. Clinical implications would be significant, since KC could be diagnosed earlier, and clinicians can develop a more comprehensive plan of treatment. The test/exam could also be combined with current imaging techniques, such as Pentacam ${ }^{\circ}$. Pentacam is currently the gold standard in anterior segment tomography and one of the most important examinations for KC suspects. In the future, PIP-focused treatments could be developed for the benefit of KC patients. Overall, a discovery such as PIP would be a breakthrough and may lead to better prevention and management of the disease.

\section{Acknowledgement}

This work is supported by US NIH/NEI grant EY028888.

\section{References}

1. Bykhovskaya Y, Li X, Epifantseva I, Haritunians T, Siscovick D, et al. (2012) Variation in the lysyl oxidase (LOX) gene is associated with keratoconus in family-based and case-control studies. Invest Ophthalmol Vis Sci 53: 4152-4157.

2. Dudakova L, Palos M, Jirsova K, Stranecky V, Krepelova A, et al. (2015) Validation of rs2956540: $\mathrm{G}>\mathrm{C}$ and $\mathrm{rs3735520:} \mathrm{G}>\mathrm{A}$ association with keratoconus in a population of European descent. Eur J Hum Genet 23: 1581-1583. 
3. Hao XD, Chen P, Chen ZL, Li SX, Wang Y (2015) Evaluating the association between keratoconus and reported genetic loci in a Han Chinese population. Ophthalmic Genet 36: 132-136.

4. Hasanian-Langroudi F, Saravani R, Validad MH, Bahari G, Yari D (2015) Association of Lysyl oxidase (LOX) polymorphisms with the risk of Keratoconus in an Iranian population. Ophthalmic Genet 36: 309-314.

5. Burdon KP, Macgregor S, Bykhovskaya Y, Javadiyan S, Li X, et al. (2011) Association of polymorphisms in the hepatocyte growth factor gene promoter with keratoconus. Invest Ophthalmol Vis Sci 52: 8514-8519.

6. Sahebjada S, Schache M, Richardson AJ, Snibson G, Daniell M, et al. (2014) Association of the hepatocyte growth factor gene with keratoconus in an Australian population. PLoS One 9: e84067.

7. Li X, Bykhovskaya Y, Haritunians T, Siscovick D, Aldave A, et al. (2012) A genome-wide association study identifies a potential novel gene locus for keratoconus, one of the commonest causes for corneal transplantation in developed countries. Hum Mol Genet 21: 421-429.

8. Bae HA, Mills RA, Lindsay R, Phillips T, Coster D, et al. (2013) Replication and meta-analysis of candidate loci identified variation at RAB3GAP1 associated with keratoconus. Invest Ophthalmol Vis Sci 54 5132-5135.

9. Lechner J, Dash DP, Muszynska D, Hosseini M, Segev F, et al. (2013) Mutational spectrum of the ZEB1 gene in corneal dystrophies supports a genotype-phenotype correlation. Invest Ophthalmol Vis Sci 54: 32153223 .

10. Mazzotta C, Traversi C, Raiskup F, Rizzo CL, Renieri A (2014) First identification of a triple corneal dystrophy association: keratoconus, epithelial basement membrane corneal dystrophy and fuchs' endothelial corneal dystrophy. Case Rep Ophthalmol 5: 281-288.

11. Li X, Bykhovskaya Y, Canedo AL, Haritunians T, Siscovick D, et al. (2013) Genetic association of COL5A1 variants in keratoconus patients suggests a complex connection between corneal thinning and keratoconus. Invest Ophthalmol Vis Sci 54: 2696-2704.
12. Stabuc-Silih M, Ravnik-Glavac M, Glavac D, Hawlina M, Strazisar M (2009) Polymorphisms in COL4A3 and COL4A4 genes associated with keratoconus. Mol Vis 15: 2848-2860.

13. Burdon KP, Vincent AL (2013) Insights into keratoconus from a genetic perspective. Clin Exp Optom 96: 146-154.

14. McKay TB, Hjortdal J, Sejersen H, Asara JM, Wu J, et al. (2016) Endocrine and metabolic pathways linked to keratoconus: Implications for the role of hormones in the stromal microenvironment. Sci Rep 6: 25534.

15. Murphy LC, Lee-Wing M, Goldenberg GJ, Shiu RP (1987) Expression of the gene encoding a prolactin-inducible protein by human breast cancers in vivo: Correlation with steroid receptor status. Cancer Res 47: 4160-4164.

16. Haagensen DE, Mazoujian G, Dilley WG, Pedersen CE, Kister SJ, et al. (1979) Breast gross cystic disease fluid analysis. I. Isolation and radioimmunoassay for a major component protein. J Natl Cancer Inst 62: 239-247.

17. Haagensen DE, Wells SA, Haider M (2000) Analysis of human breast gross cystic disease fluid protein (GCDFP) by isotope dilution RIA with solid phase (Kynar) second antibody. Proc Am Assoc Clin Chem 26: 980.

18. Caputo E, Manco G, Mandrich L, Guardiola J (2000) A novel aspartyl proteinase from apocrine epithelia and breast tumors. J Biol Chem 275: 7935-7941.

19. Priyadarsini S, Hjortdal J, Sarker-Nag A, Sejersen H, Asara JM, et al. (2014) Gross cystic disease fluid protein-15/prolactin-inducible protein as a biomarker for keratoconus disease. PloS one 9: e113310.

20. Sharif R, Nielsen SB, Hjortdal J, Karamichos D (2018) Pathogenesis of keratoconus: The intriguing therapeutic potential of prolactin-inducible protein. Prog Retin Eye Res 17: 30124-30126. 